\title{
De Luis Vives y sus impresos en la Biblioteca Pública de Toledo
}

\author{
Valentín moreno Gallego *
}

En el estado actual de la historiografía vivista, la cuestión del estudio de la vida editorial del humanista ha adquirido creciente protagonismo'. Bien reflejado incluso en exposiciones con motivo del centenario ${ }^{2}$. El conocimiento de los impresos vivesianos y su difusión es así un elemento de categoria a la hora del análisis de la presencia intelectual del valenciano.

La Biblioteca Pública de Toledo custodia una interesante colección de libros de Vives. No numerosa pero sí selecta, pues cuenta con los Opera, algunas ediciones príncipes, impresos del XVII (que son menos frecuentes que los del $\left.x V_{1}\right)$ y magníficos ejemplos del bien hacer de las prensas dieciochescas.

En los últimos años se ha realizado un serio esfuerzo para dar a conocer las abundantísimas y relevantes piezas que guarda la Biblioteca Pública de Toledo (BPT) a través de la publicación de diversos catálogos como el de Biblias del XVI, el de impresos incunables de Hagenbach, el de obras de teatro, el de libros de Derecho del $x v^{3}, y$ que se deben a

* Universidad Complutense, Madrid.

Vid. Vosters, A., "Vives al hilo de algunas portadas", Cuadernos de Bibliofilia, n." 11 (1983), págs. 25-42. González y GonzÁLEZ, E., Joan Lluis Vives. De la escolástica al humanismo. Valencia, Artes Gráficas Soler, 1987, págs. 189 ss. MORENo GaLLEGO, V., "Ediciones de las obras de Vives en el siglo XVIl». I Congreso de Jóvenes Historiadores y Geógrafos. Actas. Madrid, UCM, 1990, vol. II, págs. 91-95. Con respecto a la presencia de impresos del pensador en bibliotecas, tal vez el más reciente sea el texto de LAURENTI, J. L., "Juan Luis Vives (1492-1540) en la Biblioteca de la Universidad de llinois: Fondos raros del siglo 16 localizados", Gutenberg-Jahrbuch 1992. Mainz 1992, págs. 114-124.

2 De gran utilidad es el catálogo de la exposición Vives. Edicions princeps. Valencia, Artes Gráticas del Soler, 1992. CEP en to sucesivo.

3 Vid. “impresos de Pedro Hagenbach que se conservan en la Biblioteca Pública de Toledo", Toletum, n. 12 (1982). Catálogo de Biblias del siglo xvi que se conservan en la Biblioteca Pública de Toledo (Madrid, Instituto Suárez, 1981), Catálogo de las obras de Teatro Impresas 
la actual directora, doña Julia Méndez Aparicio. Antes ya existían el de manuscritos franciscanos, el de los manuscritos de la colección BorbónLorenzana que confeccionó F. Esteve Barba (Madrid 1942) o el de incunables, también de doña Julia (Madrid, Servicio del Ministerio de Educación y Ciencia, 1976). Huelga por tanto subrayar el calibre obvio de este centro bibliográfico, perfilado en su evolución histórica por Manuel Gutiérrez con La Biblioteca arzobispal de Toledo y su transformación en la Biblioteca Provincial (Toledo, DP, 1976).

El objeto de las líneas que siguen es comentar muy brevemente el repertorio toledano desde la perspectiva de la creación de estos textos por parte del autor, es decir, las circunstancias intelectuales de Vives cuando los redacta y, también la perspectiva bibliográfica, o sea, el relieve de los impresos a la luz de la realidad editorial de cada título. Como ambos panoramas dan para consideraciones extensas, me limitaré a las apreciaciones imprescindibles, que, por otra parte, son las más clarificadoras.

Ahorramos al lector la fría sucesión catalográfica puesto que las fichas bibliográficas de estas ediciones ya han sido recogidas en otras publicaciones ${ }^{4}$ con minuciosa pulcritud, además de que nos ocuparia el espacio, lógicamente limitado, propio de todo homenaje impreso.

Encontramos en total diecisiete ejemplares, contando duplicados, más algunos volúmenes sueltos de los Opera de Valencia. Descabalados están, de esta impresión monfortina, un juego al que falta un volumen (siete volúmenes, sign. 5941-47), otro suelto (el volumen octavo) y el tercero y cuarto (sign. 10979-80). Así, completo contamos con un solo juego bajo 4/3470-77.

La edición de la recopilación de las obras de Vives a la que nos referimos es la celebérrima de Valencia, estampada por Benito Monfort, entre 1782 y el 90 . También se la conoce por la edición mayansiana, por prepararla don Gregorio Mayans y Siscar. Don Gregorio incorporó al frente una Vita Vivis de gran importancia historiográfica ${ }^{5}$. De alta calidad tipo-

de los siglos XVI-XVIII de la Biblioteca Pública de Toledo. (Madrid, Dirección General del Libro, 1981). El de impresos de Derecho del siglo XVI es más reciente, de 1991 (Madrid, Dirección General del Libro).

4 Por ejemplo, las impresiones que corresponden a las signaturas $1 / 6652-53,3159,4 / 17293$ están descritas en LaUReNTI, J. L., "Juan Luis Vives...», op cit., pág. $118, n .{ }^{\circ} 1$ y 2 ; pág. $119, n .{ }^{\circ}$ 7 , respectivamente; las que están bajo 4/4701 (que agrupa varios textos), 4/3470-77, se describen en CEP, págs. $117,127,133$ y 212 ss. para la última signatura; y las que figuran al amparo de 4/5332, 17334 (otro ejemplar) y S.L. 2065 y 4/3498 (otro ejemplar) en MATEUY LLOPIS, F., Catálogo de la Exposición Bibliográfica celebrada con motivo del IV Centenario de la muerte de Luis Vives. Barcelona 1940 , pág. $78, n .{ }^{\circ} 53$ y pág. $54, n .{ }^{\circ} 20$, respectivamente.

5 Mayans tenía atracción por su paisano y con frecuencia lo elogia. Cfr., por muestra, "Ora- 
gráfica, no contiene los comentarios a La Ciudad de Dios, de san Agustín, como ocurre con los Opera del siglo xvi. Fue reimpresa anastáticamente en Inglaterra en los años 60 de este siglo. El ejemplar toledano está bien encuadernado de época, y con cortes jaspeados, aunque fatigada la piel. En la portada, suelta como la hoja de respeto, figura el sello de la biblioteca y el característico de la Comisión de Monumentos Histórico Artísticos de la Provincia de Toledo, como está en muchísimos libros.

La edición mayansiana aparece en un momento de gran difusión del pensamiento de nuestro hombre y, a su vez, ayuda mucho a extenderlo. Conviene recordar que la edición fue respaldada oficialmente por Real Orden del Consejo de Castilla en junio de 1780. Especialmente, en el último tercio de siglo, las impresiones de Vives se sucederán tanto dentro como fuera de España, y el humanista aparece traducido hasta en ruso, en $1768^{6}$.

La otra impresión de los Opera no es menos importante pues fue la elevación definitiva de Juan Luis como autoridad intelectual en el paisaje editorial de la época, siendo la tirada también muy amplia. Vio la luz en 1555, en Basilea, bajo la mirada de Nicolás Episcopio (1531-1565), sucesor de su padre. Igualmente, de calidad tipográfica, como la de Monfort ${ }^{7}$. El ejemplar toledano (1/6652-53) fue del infante Luis Antonio de Borbón (1727-1785), como atestigua el ex libris ${ }^{8}$. En portada presenta firma de fray Antonio Tamayo y el elogio a Conrad Gesner (clarissimi doctissimi viri) está censurado aunque es la única supresión ${ }^{9}$. Encuadernación plenamente renacentista con recuadros neomudéjares de hierros y ruedas de lacería, dispuesta como los libros del Monasterio de san Lorenzo de El Escorial, con intitulación en cortes. Faltan las abrazaderas

ción en que se exhorta a seguir la verdadera idea de la eloquencia española (1727)», Obras Completas. Oliva, 1984, vol. II. pág. 576. Entre los ejemplos manuscritos, ms. M 118 de la Biblioteca de Menéndez Pelayo (Santander): Cartas de Don Gregorio Mayans sobre el nuevo plan de estudios, y modo de estudio, escritas en 1752, fols. 14-15. Otra copia en ms. 10579 de la Biblioteca Nacional de Madrid (BNM), fols. $101 \mathrm{v}$. 105 .

6 The National Union Catalog, vol. 640 (Mansell 1979), NV 0205993. Ejemplar en la Biblioteca del Congreso de EE. UU. Se trata de la Introductio ad sapientiam.

7 Sobre Benito Monfort ver RUIz LASALA, I., Benito Monfort y su oficina tipográfica (17571852). Zaragoza 1974. Sobre Episcopio ver CEP, pág. 15 y, particularmente, VV.AA.: Contemporaies of Erasmus. Vol. I, “A-E». University of Toronto Press, 1983, págs. 437-438.

s Vid. Catálogo de Ex libris de Bibliotecas Españolas en la Biblioteca Nacional. Madrid 1989, pág. $85\left(n .{ }^{\circ} 351\right)$. Es el escudo de la Casa Real.

9 CEP, pág. 211 da unos cincuenta. No procede extenderse en Gesner pero debo decir de esta personalidad singular que es el primer bibliógrafo de Vives al abordarlo seriamente en su Bibliotheca Universalis (TIGURI, Apud Christopharun Froschovens MAXLV), por ejemplo BNM: R-36614, Pols. 430v-434v. Gesner figura en los índices inquisitoriales, por muestra, de 1571 (BNM: 2/59905), 1601 (2/60103), en los expurgatorios. 
originales. Son muchísimos los ejemplares conservados y hasta que sale la de Valencia, era buscada por eruditos y estudiosos.

El primer Vives está bien representado. Después de la atención dedicada por Jozeph ljsewijn y, sobre todo, por Enrique González, su trayectoria vital más temprana la conocemos mejor ${ }^{10}$ pues la imagen más joven se reflejaba difusa en la historiografia. El libro con sign. 4/4701 es expresión de la creación primera del humanista, en textos de impresión príncipe.

Al comienzo, las Meditationes in Septem Psalmos, quos vocant Poenitentiae. Dedica la obra a Guillermo de Croy, sobrino del señor de Chièvres, y cardenal a los dieciséis años, aunque pronto muere. Vives fue su preceptor ${ }^{11}$. Por la carta que reproduce Jiménez en el epistolario que recopiló, sabemos que su composición fue discontinua y de ahí el estilo trufado y la elaboración heterogénea ${ }^{12}$, tal como le cuenta a su pupilo desde Lovaina, en 1518. Como indica en otra carta siguiente, manifiesta que el quinto salmo le gustaba en particular ${ }^{13}$. El ejemplar toledano está incompleto al principio, falto de alguna hoja y en las dos primeras meditaciones hay comentarios marginales en latín algo macarrónico. A continuación de los salmos meditados está el De tempore quo natus est Christus, dedicado a Serafín Centellas, conde de Oliva, desde Lovaina, en diciembre de aquel 1518, y junto al texto siguiente, el Clypei Christi descriptio ${ }^{14}$. En el primero se nota un interés por los presupuestos agustinianos con respecto al pensar histórico, precedente del Vives comentador de san Agustín, y el segundo es una especie de historia biblica donde sale a relucir América indirectamente y donde utiliza retóricamente la imitación a Virgilio.

Sigue el Christi Jesu Triumphus y la Virginis Dei Parentis Ovratio. Es la misma pieza en dos partes. Otrecida a Bernardo Mensa, obispo de Heln, desde París, en 1514. Aunque la primera se imprimió en Brujas, se compuso en París hacia 1514, pero retocada en Lovaina en el 19. Además,

10 IJSEWIJN, J.: «J. L. Vives in 1512-1517. A Reconsideration of Evidence», Humanistica Lovaniensia, 26 (1977), págs. 82-100. GonzÁLEZ, E., Joan Lluis..., págs. 103 ss.

Vid. Moreno Gallego, V., Juan Luis Vives en la España postridentina de Felipe II. Tesis de licenciatura inédita. Madrid 1991, págs. 146-47. Ya WATSON, F., España, Valencia y Luis Vives. Valencia 1932, pág. 19 y ALVENTOSA, fray Juan de (OFM), «Bibliografía vivista», Ofrenda de los Antiguos "Amigos» en su IV Centenario. Cátedra "Luis Vives" de la Facultad de Filosofia y Letras. Valencia 1940, pág. 116, destacan con especial relieve la influencia de Vives en el joven Guillermo.

12 Jiménez Delgado, J., Epistolario. Madrid, E. Nacional, 1978, carta n. ${ }^{\circ}$ 10, pág. 127.

13 Ibidem, carta n. ${ }^{\circ} 12$, pág. 133.

14 Ibidem, carta n. ${ }^{\circ}$, págs. 124-25. 
sale a relucir Erasmo y hasta 1517 no se conocen. El mensaje es que la verdadera heroicidad es la espiritual y no la de la gloria militar, poniendo el modelo de César. Después, Veritas fucata y Anima senis, donde condena la poesía de entretenimiento vanal ${ }^{15}$. Ambas dedicadas a Juan de Cromunas, abad de Santiago, cerca de Lieja, en 1519. En el segundo opúsculo, también compuesto en París, se introduce en la senilidad como conocedora de la sabiduría. Dedica al conde de Nueva Águila un texto que sigue, de más relieve, De initiis, sectis, et laudibus philosophiae pues es una cierta aproximación a la historia crítica de la filosofía. Hecho en Lovaina en $1518^{16}$.

La Fabula de homine y la Praelectio in Georgica Virgilii las dedica a Antonio de Berges. También confeccionadas en 1518, en Lovaina. En la primera defiende la idea del hombre como protagonista del mundo y parece muy inspirada en el De hominis dignitate de Pico della Mirandola. EI segundo tratado es fruto de la docencia privada que ejercía ${ }^{17}$.

Sigue en el cuerpo del libro el Genethliacon Jesu Christi. Tal como figura en la carta que recoge Jiménez, se compuso el 1 de enero de 1518, como aguinaldo a Juan Briard, vicerrector de la Universidad de Lovaina ${ }^{18}$.

In leges Ciceronis Praelectio y el Aedes legum son dedicados a Martín Poncio, jurisconsulto. En la primera, muy basada en el Derecho Natural, nos muestra al Cicerón del Derecho y su repercusión social la ve en el Aedes. Sobre el Derecho en Vives es interesante la tesis doctoral de August Monzon leída en Valencia en 1987. El Pompeius fugiens fue dedicado en abril del 19 a Carlos Carendoleto. Es una pieza moralista con ribetes de estoicismo. Nuestro ejemplar tiene alguna glosa marginal. El Inpseudodialecticos estaba concluido en febrero de ese año ${ }^{19}$ y ya es obra de calado. Muestra un renacentismo radical atacando la lógica terminista y el nominalismo rígido, que practicó en su estancia parisina. Erasmo aconsejó su lectura a Tomás Moro y desde entonces gozará de la alta estima de Moro. Por último, In Somnium Scipionis, con sus siete partes, centradas en Cicerón y dedicadas al designado arzobispo de Valencia, Erardo de la Marca ${ }^{20}$. A veces, corren impresas sueltas. Antes de comenzar el Somnium, figura el bello escudete de Teodoro Martín Alostense, el impresor de todos los opúsculos anteriores, conocidos en su agrupación como

15 Ibidem, carta n. ${ }^{\circ} 18$, págs. $149-50$

16 Ibidem, carta n. ${ }^{\circ} 13$, págs. 136-37

17 lbidem, carta n. 11 , pág. 131 en relación con la Fabula.

18 lbidem, carta $n .0^{\circ} 8$, pág. 123.

9 Ibidem, carta n. ${ }^{\circ} 15$, pág. 143

20 Ibidem, carta n. ${ }^{\circ} 22$, pág. 166 
Opuscula varia, y aparecidos en Lovaina. El Somnium lo imprimió el reputado Juan Froben en 1521, en Basilea, y su carácter es de adoctrinamiento moral y filosófico para el irombre de gobierno.

Pero además de estos dos núcleos textuales, el ejemplar que para junto al Tajo se ve engrosado en último término con las Declamationes Sullanae quinque, aparecidas en abril de 1520 en las prensas antuerpienses de Miguel Hillenio. Al frente de las Declamationes están las palabras de Erasmo: «Mientras otros gritan, Vives declama con sabiduría y serenidad únicas...". El método y concepto de la filosofía queda expuesto en las frases del prefatio. Corregida esta edición primera vuelve a salir en 1538, por Roberto Winter, otro impresor basileense, acaudalado y pariente de Oporino, otro soberbio impresor de Vives, con el que se asoció y se separó luego. El año 1538 es fundamental en la vida intelectual y editorial del pensador.

Aunque las tres obras están juntas en el 4/4701 (que se nos aparece en pergamino, con numerosas cuentas en guardas superiores y parte del texto de una carta de 1714 en las mismas), lo normal es que también corran sueltas: la Opuscula varia está suelta en la Biblioteca Real de Bruselas, en la British Library, en la Pública de Nueva York o en la Nacional de Madrid (R/20400). Asimismo, el Somnium ${ }^{21}$ y las Declamationes ${ }^{22}$, que fueron traducidas al italiano y publicadas en 1549 con éxito por los hermanos De Nicolini da Sabio (Venecia). El traductor fue Domenico Tarsia ${ }^{23}$.

Por tanto, el primer Vives está muy reflejado en Toledo, faltando algunos otros textos breves como el Sapiens, el Convivia, el Aureum, la epístola a Barlando, la vida de Dullardo o la praelectio a Juan Fort, que forman su escritura inaugural.

Cronológicamente, la siguiente obra que se nos regala, y de más entidad, son los comentarios a los XVII libros del De Civitate Dei agustiniano (sign. 4205). De enero a julio de 1521 redactó lo relativo a los seis primeros. En enero del 22 manda para imprimir siete, en abril diez más, y el resto en julio del 22. Fue una elaboración compleja para Vives: afectado por situaciones familiares y muy sensible a las crisis políticas de la situación internacional, hizo un gran esfuerzo como escoliador de Agustín, durmiendo muy poco y cayendo enfermo. Además, no será muy del agra-

21 Vid. Biblioteca de Cataluña: 13.11.2; BNM: R/9659; Fac. FF y LL de UCM: 13914 y 11390 ; Universitaria de Valencia: Z-4/98.

22 Colombina: 6.3.39; British Library (BL): 721. f. 2 y la carta de Erasmo censurada en, por ejemplo, BNM: R/2688.

${ }_{23}$ Localizamos 32 ejemplares en nuestra tesina, Moreno, V., Juan Luis Vives..., pág. 238. 
do de Erasmo la producción. El de Rotterdam le había ofrecido participar en la edición de los Opera del Hiponense, y no volverán a participar juntos en otra empresa, aunque en el 29 Erasmo le proponga comentar a Séneca.

En su escritura vertió, un Juan Luis ya más maduro (contaba los treinta años), un importante sentido histórico al texto de Aurelio Agustín. Su rica erudición grecorromana, aunque densa, no es pesada y dota a los libros comentados de un serio soporte interpretativo ${ }^{24}$. La pieza toledana es primera edición, en Basilea, por Froben, en septiembre de 1522. Este ejemplar no está censurado, lo cual no es excesivamente frecuente, pues muchísimos corren censurados. Esta creación intelectual de Vives fue la única ordenada expurgar ${ }^{25}$. El libro está restaurado en portada y punto de polilla que afectaba a las quince primeras hojas. Encuadernación actual en rústica, de cartulina recubierta de papel aunque con cordones. En portada se indica que en 1714 era del párroco de Ntra. Sra. de la Varga, en la villa de Uceda, don Bernardo Mateos.

La edición conservada de De Institutione foeminae christianae es la mejor del siglo XVIII, probablemente (S.L. 2397-98). Desde Brujas, la dedica a Catalina de Inglaterra ${ }^{26}$. Juan Luis pretende dar a la princesa María un compendio de cómo debe ser y comportarse una mujer cristiana en sociedad. Su redacción le alivió económicamente. Fue traducida por Richard Hyrde, tutor de los hijos de Moro ${ }^{27}$. La edición que comentamos es en dos volúmenes, de la viuda e hijo de Marín, y de Madrid 1792. Es la traducción del Anónimo de Alcalá, 1529, distinta de la de Juan Justiniano (Valencia 1528). En el prólogo del editor se encarece el valor de la obra y le asocia a Gesner como restaurador "de las Artes y las Ciencias". El prólogo es completo, pues trata de sus traductores en varias naciones y

24 Es muy probable que en pocos meses aparezca "Judaísmo y Catolicismo en el Renacide los comentarios a De Civitate Dei, de san Agustín, por Juan Luis Vives", texto presentado en el Congreso Internacional "Literatura del Siglo de Oro de los judios fuera de Españam, celebrado en diciembre de 1992. Los articulos qu al comento DCD Luis escoliador de Agustín no son escasos y alli los recogems: "Une collaboration inconnue entre es de valía el repertorio y aproximacte en 1544: le De Civitate Dei Dei d'Agustin édité par Juan Caroline Guillard et Hugues de La Porte págs. 126-139. Conocimos su existencia con posterioLuis Vives", Gutemberg-Jahrbueh 1988, paso, proporciona datos diferentes y las consideraciones ridad a la comunicación,

25 Vid. supra $0^{\circ} 24$ donde se alude a la cuestión de la censura

26 JiMÉNEZ, J., Op. cit., carta n. ${ }^{\circ} 60$, pág. 302.

27 Pasan de 50 las ediciones de este título mayor de Vives a lo largo del XVI. Vid. MORENO, V., Op. cit., págs. 247-50. Hubo siete impresiones de la traducción Hyrde en la centuria, todas de Londres. Esta obra contó con otros traduct impresa de Luis Vives en el Quinientos: Index Hispania 
observa cómo difieren en España las dos traducciones, pues en la de Valencia se suprimieron algunas frases sobre la madre de Vives, que él incluía en el texto.

Es edición rigurosa, de excelente impresión, deliciosa, y el ejemplar es estupendo, muy limpio y encuadernado de época en pasta valenciana, lustrosamente. Se incluye al final una clista de algunas voces y modos antiguos o poco usados que se halla en esta Obra», muy útil para el lector profano ${ }^{28}$.

El De Subventione pauperum también se nos presenta en la espléndida edición de Benito Monfort (Valencia 1781) con el título Tratado del Socorro de los Pobres. El día de Reyes de 1526 es ofrecido el libro a los burgomaestres de Brujas ${ }^{29}$, a la que considera su casa tras catorce años de estancia alterna pero fiel. Parece que lo redacta a fines de 1525, en los dos meses últimos. Ya en Inglaterra le dio vueltas al asunto. La príncipe fue bastante incorrecta tipográficamente y es más de fiar la de Lyon del 32, que se puede considerar edición tipo.

Hay más de una decena de impresiones en el XVI y se tradujo al italiano, también por Tarsia en el 45 y al francés en el 83, por Girard ${ }^{30}$. Esta impresión es una muestra soberbia de la imprenta del XVIII en España y está en la categoría de, por ejemplo, el Quijote de la Real Academia (1780). En la Pública de Toledo hay dos ejemplares: el 4/3498, impecable y con bellísimas guardas de agua y los cortes en otros colores. En plena piel sin nervios, pero finos dorados, algo rozada. Tejuelo dorado y en los planos una sencilla fantasía. El S.L. 2065 (S.L. significa Sala de Lectura) en pergamino a la romana y firma de anterior propietario, "Juan Antonio Rodrigálvarez", también en excelente estado. El "Aviso" es de Mayans, aunque no figura. Se trata del traslado que hizo Gonzalo Nieto en 1526, seguramente, aunque nunca impreso hasta 1781 , pues el manuscrito se perdió y se recuperó por entonces. Mateu y Llopis lo describe ${ }^{31}$. En portada, excelente grabado del rostro de Vives.

De concordia et discordia in humano genere está en Toledo en su edición príncipe (sign. 3159), de Amberes, 1529, por Miguel Hillenio. Sin embargo, sin portada, y falto de una hoja de texto. La acompañan, como

28 Bonilla y San Martín, A., Luis Vives y la filosofía del Renacimiento. Madrid 1929, vol. III, pág. $196, n .^{\circ} 56$, recoge y describe someramente la edición resaltando su valía, aunque la cree de la traducción de Justiniano.

29 JIMÉNEZ, J., Op. cit., carta n. ${ }^{\circ} 103$, pág. 416.

30 Moreno, V., Op. cit., págs. 253-54.

31 Mateu, F., Op. cit., pág. 54, n. 20. 
no es raro, el De pacificatione y De conditione vitae christianorum sub Turca, también de Hillenio. En pergamino de época y protegido con caja de cartón.

Desde fines de 1528 reside establemente en Brujas, abandonando Inglaterra debido a sus serias diferencias con el rey. El De concordia fue escrito a ratos entre 1526 y el verano del 28 , aunque hasta el 29 no se publica, dedicándolo a Carlos $V^{32}$. Desde una perspectiva de moralismo político, recuerda los bienes de la concordia entre los príncipes y los males de la discordia, seguramente a la vista del enfrentamiento entre Francisco I y Carlos, y a resultas de Pavía. Continuación natural es De pacificatione dedicado al Inquisidor General Manrique, aunque por entonces, los restos de su madre son exhumados y quemados, tras incoársele proceso por el Santo Oficio. El texto vivesiano se encuadra en el marco ideológico de la Querella pacis erasmiana, de los diálogos de Valdés y de la influencia de los libros de Nicolás de Cusa, De concordia catholica y De pace fidei. Además de la situación internacional, le influyó la actitud de Enrique VIII, provocador de discordias, a sus ojos, en el seno de la Cristiandad. El De conditione sirve para centrar la atención política no sólo entre los príncipes cristianos sino ante el Turco.

El De concordia fue impreso en el XVI una decena de veces, aunque el mayor número de ejemplares conservados es de esta príncipe. El De pacificatione sólo consta por tres tiradas (la primera, la de Lyon de 1532 , y Frankfurt 1578). El De conditione rara vez fue impreso tras esta ocasión $^{33}$.

De disciplinis es una de las grandes obras vivesianas. En ella, Juan Luis, ya maduro, teoriza sobre la enseñanza, la psicologia, la historia, el buen humanista, etc. En BPT la de Lyon de 1551, por Juan Frellonio (4/ 17293). El ejemplar estuvo en la Casa Profesa de la Compaña de Jesús en Madrid, y luego en un instituto de segunda enseñanza. Pobre. Mucho se Encuadernación de fines del XVIII o comienzos del xIX, plaber saber de ha escrito sobre $D e$ disciplinis, verdadera enciclopedia época.

En julio de 1531 la dedica a Juan III de Portugal ${ }^{34}$, y la compuso poco antes, en dos partes. La primera, De causis corruptarum artium con sus

32 JiMÉNEZ, J., Op. cit., carta n. ${ }^{\circ}$ 143, pág. 520.

33 Por ejemplo, otras impresiones en el Monasterio de san Lorenzo de El Escorial: 57. IX.15 (3) y, antes, de 1538, 17.V.8 (7). El tamoso ejemplar Maioli o Mahieu, vendido en Paris en 1894 por 2900 francos (PALAU, A., Manual del librero hispano-americanoBarcelo encuadernada.

XXVIII, pág. 417) lo posee hoy B. March (sig 
siete libros y la segunda, De tradendis disciplinis, en cinco. Más otra tercera, De artibus, en ocho libros, que se pensó aparte pero se incorporó al cuerpo de la príncipe. A veces se han impreso fragmentariamente. Es rico como fuente histórica, pues permite conocer textos y autores manejados entonces ${ }^{35}$. Obra capital en Vives por el despliegue de conocimientos y su peso específico en diversos campos: pedagogía, psicología, teoría de la historia.

Tuvo al menos seis ediciones en el $\mathrm{xVI}$, siendo las de más ejemplares conservados la primera de 1531, de Hillenio (Amberes), que es un estupendo balcón para asomarse a la mejor tipografía de aquellos años, y ésta del 51 , con una veintena de ejemplares registrados ${ }^{36}$.

De los afamados diálogos de Vives no hay ninguna representación del siglo XVI, lo cual es raro pues rondaron las 170 ediciones. Pero hay dos muy raras del XVII, y tres del XVIII. Redactados, seguramente, a fines del 38 e inicios del 39 en Breda, ve la luz en Basilea en marzo, por Roberto Winter, pero es tal el éxito que ese mismo año se reimprime en París y Amberes ${ }^{37}$. También se ha escrito bastante sobre estos diálogos. En ellos, Vives aplicó metodológicamente algunos presupuestos de De disciplinis. La tradición de los diálogos escolares era duradera, pero el valenciano la reimpulsó. La obra más difundida de Vives fue dedicada al príncipe Felipe ${ }^{38}$. Concebida para ser útil instrumento para aprender latín, desde los primeros 50 irán acompañados de la carta de Pedro Mota, profesor complutense, y el vocabulario de Ramírez. Es pieza fundamental en la historia de los textos docentes, e influyó en la composición de otros diálogos, como los de Juan Maldonado. En total, veinticinco diálogos donde combina asuntos cotidianos con cuestiones más elevadas.

Las ediciones del XVII son las de las signs. 22210 y 24625 . La primera es de Juan Keerbergio, de 1616 y antuerpiense. Pergamino de época y en portado "Año del Señor de 1720". Mal papel, como muchas del XVII y desde páginas 149 en mal estado, con pérdida de márgenes.

La segunda es de Zaragoza, 1607, por Juan Quataneo. No hay alusión a él en La imprenta en Zaragoza, de I. Ruiz Lasala (Zaragoza 1975). Sin embargo, tenemos noticias de él en el Ensayo de Jiménez Catalán ${ }^{39}$, que

35 Vid. Esteban, L. y López MARTín, La escuela de primeras letras según Juan Luis Vives: estudio, iconografía y textos. Valencia, Martín Impresores, 1993.

36 Moreno, V., Op. cit., págs. 259-60.

${ }_{37}$ CEP, págs. 192-93. No es descabellado pensar en la posibilidad de una anterior a esa de marzo, hoy perdida.

38 JIMÉNEZ, J., carta 177, pág. 612.

39 Jiménez CAtAlán, M., Ensayo de una tipografía Zaragozana del siglo xvit. Zaragoza, Ti- 
lo identifica como Juan Lanaja y Quartanet. Dice que imprimió continuamente de 1610 al 39 , siendo su primera impresión la de 1608 de las Cincventa oraciones funerales, del P. Luis de Rebolledo (ejemplar en la Universitaria de Zaragoza). Es evidente, por tanto, que no conoció ésta de 1607, que debe ser su estreno en la imprenta. Es lógico que se quisiera iniciar con un título de demanda y así no es raro que no haya mudo
ejemplares conservados. De hecho, sólo se ha localizado el toledano, hasta ahora.

Lanaja fue impresor conocido, que trabajó para la Universidad y se estableció junto a la Seo. Entre los dieciséis títulos que da Jiménez, no cita el de Vives de factura suya pero sí libros de Zurita, Gonzalo de Céspedes y $L$. Leonardo de Argensola. Otros de su dinastía Lamarca. La pieza Lanaja, Pedro Lanaja y Quartanet y Pedro Lanaja y La y está corto de Lanaja, Pedro Lanaja y Quartane en portada, de antiguo, y está corto de
toledana tiene pérdida de texto en póno
márgenes, aunque resto buen ejemplar, en pergamino de época protegido.

Las impresiones vivesianas son menos en el XVII que en el XVI, con gran diferencia. Si en el XVI pudo haber unas 700 , en el siglo XVII habrá un centenar largo o dos, pero no más ${ }^{40}$, de ahí su mado otros ejemplares. en el caso concreto de estas dos no hemos localizadón de los diálogos Es muy probable que en BPT esté la primera salidas que se produjeron impresos en la Ciudad Augusta, pue la muger christiana $(1539,45$ y 55). en el XVI fueron de la Instrucion ediciones de esta obra (los coloquios) en En el XVII hemos constas en España, en una decena más ${ }^{41}$, por lo menos.

Del XVIII hay tres ediciones. La de 1704, también zaragozana, de Mateo de la Bastida, con dos ejemplares: 18129 y 25700; la de Valencia, de 1749 , por la viuda de Jerónimo Conejos, tambienncisco Manuel de Mena 17334 y 4/5332; y la de Madrid, de 1762, de Francisco Manuel de Mena (S.L. 701).

a Académica", MCMXXV. Al dar las fichas del año 1607 no recoge el libro, págs. 91 informa sobre Lanaja y reproduce algunos documentos.

40 MOREno, V., "Ediciones...", op. cit. Se han alterado cifras dadas en 1988 pero la idea de escasez en el XVII frente al XVı es válida totalmente. Barcinone, Expensis Sebastiani à Comellas, 41 Matriti, Typogr. Regni, 1632 (BNM: 2/68088); Barcino (BNM: 7/16543); Matriti, F. Garriae, 1643 (BNM: 3/21376); Valencia", Vicentino Cabrerleria, 1670 (BL: 1568/6541); Valencia, Marçal, 1644 (BNM: 3/34745); Barcinone, Antonij Laca 1640 (NUC, pág. 361); Madrid, Lucas Bedmar, 1642 (Palau, pág. 428); Alcalá, M. Fernández, (Palau); Lerman, J. B. Varesio, 1619 (BNM: 261942 1670 (Palau); Zaragoza, Diego Latorre, 1627 (Pala); Barcelona, 1615 (Palau) y Madrid, Francisco y otro en la Universidad de Salamanca 1/33ica), no en la tesis de Yolanda San Román Impresos

Garcia, 1619 (en Hispania of Society ACM, 1992).
madrileños de 1566 a 1625 (Madrid, UCM, 
El 18129 tuvo que ser en el xvill de un pastelero o amante al dulce, pues afirma que si se perdiese, su propietario, Juan Pablo José Carbón, recompensaría con un pastel, como se dice curiosamente en guarda anterior. En la posterior, otro dueño. Buen estado salvo el pergamino, algo mal. El 25700 está despegado del lomo, en pergamino. Alguna glosa marginal. Fue de un bachiller en Sagrada Teología, Manuel López. Y de un tal Francisco Morales que ofrece «lo que fuere y lo que Vm. pidiere A su cargo" en caso de pérdida. Se firma en Fuensalida, el 13 de marzo de 1713.

Esta edición tiene mal papel. Y no es rara ${ }^{42}$. La de Valencia, 1749 , es la segunda edición de la traducción de Cristóbal Coret y Peris, presbítero y profesor de latinidad en la iglesia metropolitana de Valencia. Corrigió el texto y añadió notas con respecto a la primera. Dedica los diálogos a santo Tomás de Villanueva, "exemplar de prelados». La describe Mateu ${ }^{43}$. Confronta texto latino con castellano, lo cual es útil. El 4/5332 es buen ejemplar. Proviene de la Biblioteca Arzobispal. El 17334 en peor estado. El de Madrid, 1762, es muy limpio pero corto de márgenes. Francisco Manuel de Mena fue impresor y librero de importancia. En el Archivo Histórico de Protocolos de Madrid (AHPM) hemos encontrado algunos datos de este potente librero. Tasador de tiendas de libros en su traspaso y fiador en alguna que otra compra de librerías ${ }^{44}$, hereda de su suegro Francisco Rodríguez la librería, en 1754, en Madrid, y sigue con ella ${ }^{45}$. Ayudó a reactivar el mundo de la imprenta y comercio del libro en Madrid, algo decaído a mediados de siglo.

El último libro escrito por el humanista, De veritate fidei christianae, también se guarda en el caserón toledano. Se trata de la de Basilea de junio de 1544 por Juan Oporino (sign. 3313). Ejemplar restaurado con encuardernación imitando a la original y realizada por el Centro Nacional de Restauración de Libros y Documentos. Hubo una decena de impresiones en el xVI. Es la segunda ésta, de la que hemos encontrado dieciséis ejemplares ${ }^{46}$. La príncipe es de igual ciudad e impresor pero 1543. Juan

\footnotetext{
42 En BNM tres: 2/20932, 2/37537 y 3/47004. En el NUC, NV 0205853, ejemplar en Bryn Mawr College, Bryn Mawr.

${ }_{43}$ Mateu, F., Op. cit, pág. 78, n. ${ }^{\circ} 53$.

44 AHPM, prot. 18129 , fols. $417-422 v$. En diciembre de 1750 tasa la importante libreria de D. María Sáez Duque, viuda de Alfonso Vindel para su venta al mancebo Juan Esparza, en 114.503 reales pero se ajustó la venta en 40.000 reales por "bajar mucho" el comercio de libros últimamente, y no ser de fácil salida los libros almacenados. Mena dio el dinero a Esparza, que le terminó de pagar en 1757 , a razón de 6.666 reales cada año.

${ }_{45}$ El inventario de la librería heredada en AHPM: prot. 18132, s/f. Son varios cientos de libros, inventario copioso. Se tasaron en 17.395 reales.

46 Moreno, V., Juan Luis..., pág. 276.
} 
Oporino, junto a Roberto Winter y Juan Froben, es el que más veces 10 estampa a lo largo de la centuria.

Ya hacia 1535 preparaba el De veritate, aunque no lo concluyó del todo y parece que su gran amigo Francisco Craneveld la limó antes de que la publicara. Cranavelt la dedica a Paulo $11 \mathrm{I}^{47}$. Vivo apologético. A samente en la composición de este importante tras conceptuaciones aunlargo de cinco libros, vierte con y al Islam es arisco y duro, utilizando la que con respecto al judaismo dialogada en los libros III y IV.

Tras esta visión de la obra del levantino que se conserva en la Pública de Toledo, concluimos que el Vives estante en la Ciudad Imperial es representativo aunque incompleto. Es una colección intos, pero recordemos al principio, al reunir príncipes, raras e impreso títulos en su producción. que el pensador tiene casi una sesente ejemplar de la Introductio ad saAsombra que no encontremos ningún de Linguae latinae exercitatio del pientiam además de ninguna icones del XVI y del XVIII, en su número, y la $X V I$. La casi igualdad de refleja un poco la evolución de la difusión del humanista. Además, en algunos del XVI figuran firmas y datas del XVIII, lo humanista. Además, en algunos del $\mathrm{XVI}$ figuran factualidad intelectual ya antes
que puede indicar su recuperación para la acto a nivel popular ${ }^{48}$.
del auge de la segunda mitad de ese siglo, a nel primero, el más fresco; el

Pero el Vives de esta gran biblioteca es el primero, el más fresco; el filósofo del Derecho, el espiritual, el estudioso de Cicerón agustín, el teórico de la pedagogía y el metodólogo de la docencico y el apologeta. Y pauperismo, el moralista social, el opusculista pus caras creativas giran también el último Vives, el madue esperan, hasta que llega un curioso a saludarlos, en el atractivo miradero.

carta ${ }^{\circ} 191$ pág. 634. En 1991 presenté al Congreso Internacional aJudios y ConvéNEZ, J., caristoria" (Ribadana) una comunicación sobre el judaísmo en esta obra, en concreto en el libro III. En prensa, «Humanismo y fe en el Congreso de Humanistas Españoles, de Luis Vives, y sus impresiones", comunicacion entre otros aspectos relativos a este destacado donde se trata de las ediciones de De veritate entre or dición de los siglos XVI y XVII durante texto.

48 JuÁrez Medina, A., Las reediciones de obras de eruducción", págs. 1-10, algún juicio de el siglo XVill español. Frankfurt am Main 1988. En la “lntroduccionn, pags. 1-10, algün juicio de interés. 